\title{
Old or Age Indeterminate Posterior Myocardial Infarction by ECG Finding
}

National Cancer Institute

\section{Source}

National Cancer Institute. Old or Age Indeterminate Posterior Myocardial Infarction by

ECG Finding. NCl Thesaurus. Code C102691.

An electrocardiographic finding in leads V1 or V2 of an initial R wave duration greater than or equal to $40 \mathrm{~ms}$, R wave greater than S wave, and upright T wave, which is suggestive of myocardial infarction of the posterior wall of the left ventricle, without evidence of current or ong oing acute infarction. Evidence of inferior or lateral myocardial infarction is usually also present. (CDISC) 